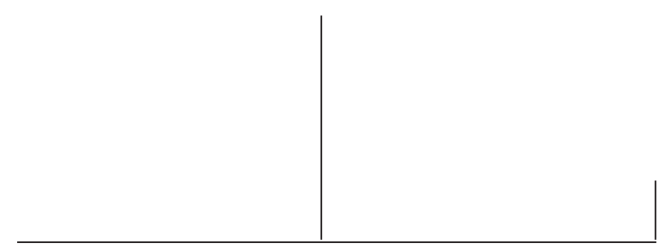

Rev. Latinoam. Psicopat. Fund., X, 3, 483-494

\title{
Saídas do hospital: trabalho psicanalítico com pacientes de longa permanência em internação psiquiátrica*
}

\author{
Nelisa de Araújo Guimarães
}

\begin{abstract}
Pacientes com graves desordens mentais devem ser respeitados como cidadãos. Um trabalho de enfoque psicanalítico é realizado em equipe multidisciplinar com grupos de pacientes que estão saindo do hospital psiquiátrico e procurando um novo modo de vida. Laços sociais e posições subjetivas são efeitos positivos observados.

Palavras-chave: Psicanálise, Hospital Psiquiátrico,

saída de internação, subjetivação na psicose
\end{abstract}

* Projeto e Relatório de pesquisa para FAPERJ - Fixação de Pesquisador Nível 3 Projeto "Cidadania e Saúde Mental: catástrofe subjetiva, exclusão e reabilitação". Trabalho apresentado em mesa-redonda "A psicanálise e as práticas de atenção psicossocial: questões para uma clínica renovada". Tema do trabalho: "Da catástrofe subjetiva à singularidade - passagem da internação à moradia assistida", apresentado no II Congresso Internacional de Psicopatologia Fundamental e VIII Congresso Brasileiro de Psicopatologia Fundamental, 7-10 de setembro de 2006. 


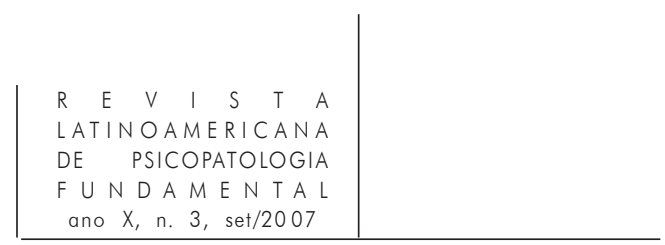

\section{Introdução - cidadania e saúde mental}

Com as perspectivas abertas pela Reforma Psiquiátrica no Brasil, encontramos saídas amplamente humanizadas para pacientes egressos do regime asilar. No campo da saúde mental, a situação de cidadania destes pacientes pode ser recuperada por tantas aberturas, entre as quais se situam os Serviços Residenciais Terapêuticos, que hoje constituem uma alternativa em crescimento neste campo. A pesquisa que dá origem ao presente artigo procura desenvolver um novo método de trabalho: apoio conceitual e metodológico para trabalhadores da saúde mental, que estão envolvidos com a preparação dos pacientes de longa permanência para a saída do hospital psiquiátrico, e para a entrada numa nova condição de vida como moradores de um SRT - Serviço Residencial Terapêutico.

A aproximação entre situação asilar e exclusão do exercício da cidadania coloca problemas especiais no âmbito da subjetivação. A saída da situação asilar para a construção do exercício próprio de uma posição de autonomia sem tutela exige o enfrentamento de tais problemas e a elaboração subjetiva das soluções necessárias.

No amplo trabalho de inclusão social e de construção da cidadania, situa-se o trabalho específico com a saúde mental dentro do processo de saúde, na perspectiva de produção de qualidade de vida: são os princípios e as diretrizes, definidos na III Conferência Nacional de Saúde Mental (2001), que possibilitam o desdobramento de muitas ações de reabilitação.

A ação proposta na pesquisa realizada pretende colaborar na reabilitação de pacientes graves, egressos da internação psiquiátrica, participantes de programas de reconstrução da cidadania. Pretende realizar o trabalho psíquico de elaboração de sua saída da situação de internação no Instituto de Psiquiatria para a construção de novas posições psíquicas no processo de reabilitação social. Como cada paciente pode enfrentar a sua saída? Como cada um pode construir um futuro? 
O ponto de partida da ação proposta é a existência de pessoas que foram internadas na instituição, estão em situação de internação em preparação para saída, com grandes dificuldades para assumir uma vida própria, para conviver com outras pessoas e com suas famílias, para realizar trabalho e outras atividades sociais.

A ação proposta pretende começar por uma situação de urgência ou de catástrofe subjetiva para seguir até um começo novo. Iniciar pelo começo de uma nova etapa de vida é o trajeto inverso das diretrizes e dos projetos (que visam resultados), mas é o trajeto necessário para as mudanças de fato. Desde o começo, esta ação se dirige para as diretrizes mais gerais de reconstrução da cidadania, colocando a idéia de mortos-vivos (Zizek, 2002) como modo de indicar a experiência de exclusão social vivida pelos pacientes mencionados.

O começo importante aqui é o início de qualquer processo de subjetivação e novo laço social, de qualquer processo de existência humana com reconhecimento e inclusão.

A pesquisa pretendeu descrever:

- as condições encontradas na vida psíquica das pessoas atendidas;

- as condições obtidas no final da experiência do grupo para preparação de um projeto de vida;

- uma análise dos processos de subjetivação e de laço social.

\section{As referências teóricas e a realização da pesquisa}

A pesquisa define as condições encontradas na vida das pessoas atendidas: os pacientes (26 entre 2005 e 2006) foram selecionados pela médica psiquiatra Maria Tavares Cavalcanti, diretora clínica do Instituto de Psiquiatria, coordenadora de um projeto de serviços residenciais terapêuticos. Vinte reuniões foram realizadas com dois grupos, no processo de preparação subjetiva da transferência desses pacientes do hospital para a moradia ou para situações particulares de saída.

Os grupos são formados por pacientes com diagnósticos no campo da psicose em geral, com longa permanência em internação psiquiátrica no hospital do IPUB - Instituto de Psiquiatria da Universidade Federal do Rio de Janeiro, e outros hospitais, e com a participação de outros profissionais envolvidos no tratamento desses pacientes. O objetivo da minha coordenação de vinte reuniões desses grupos foi realizar a sua preparação subjetiva para uma nova etapa de vida, com a saída do hospital e um novo início de vida, e realizar a pesquisa das posições subjetivas como efeito de um trabalho psicanalítico conduzido nas reuniões de preparação. A pesquisa pretende ainda levantar hipóteses sobre a aplicação da 


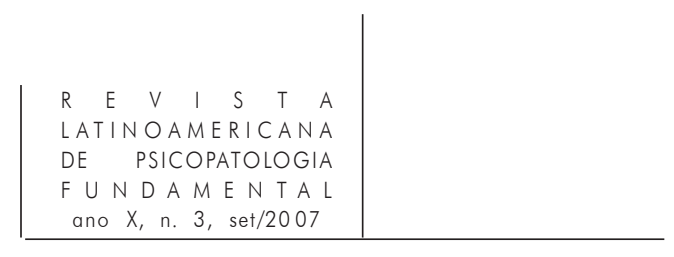

psicanálise no trabalho da Saúde Mental e oferecer um modelo de atendimento complementar aos trabalhos de recuperação e reabilitação de pacientes graves internados em instituições psiquiátricas e outras.

Foram realizados estudos, apresentações em reuniões de pesquisa, participações em reuniões clínicas da instituição, supervisões e aulas no Curso de Especialização em Clínica Psicanalítica, orientação de monografias e participação em bancas de defesa. Toda a orientação do trabalho direcionado para a pesquisa em questão, e para a colaboração com o trabalho da instituição, foi feita sob supervisão da coordenadora de ensino e pesquisa Ana Cristina Figueiredo.

O primeiro grupo de pacientes da pesquisa foi nomeado Grupo Morar Junto por P., 54 anos, internado desde os 30 com diagnóstico de esquizofrenia. Acompanhamos, no grupo, sua participação animada e lúcida nos comentários sobre uma nova possibilidade de vida, seus pedidos de regularização da documentação e de verificação médica de sua constipação. Insistimos com sua prima, única pessoa viva de sua família, para estar mais presente e atuante, e também insistimos com médicos e assistentes sociais da instituição para concluírem intervenções e diagnósticos em aberto. Finalmente, depois de um ano na moradia, P. terá sua carteira de identidade, passará os direitos de receber uma pensão para a prima, e enfrenta já as condições irreversíveis de uma doença incurável em estado terminal.

Confirmamos nos pacientes uma colocação atual pensada pelo autor, filósofopsicanalista, Zizek (2002) com o termo mortos-vivos. É um significante apontando para situações de apagamento subjetivo, como a dessubjetivação promovida pelas rotinas hospitalares, que também ocorrem em experiências devastadoras como o Muselmann dos campos de concentração, indicado por Agamben (1995), ou talvez dos campos de refugiados ou de terras ocupadas, ou ainda das situações de exclusão social e política. Como ocorre na situação asilar.

A colocação de Agamben sobre o Homo Sacer inspira a análise de Zizek dos mortos-vivos, aqueles que não se incluem numa ordem legal, ou numa situação de plenos direitos à cidadania.

Correlativamente às regras humanas e sua obscenidade como supereu em ação nas situações de sobrevivência dos mortos-vivos, colocam-se as dimensões do impossível e do vazio - o deserto do real de Zizek, acompanhado de figuras de terror e da existência apavorante da catástrofe. Deserto do real, mundo das identidades e da existência, onde se trava permanentemente o embate do que insiste para se tornar existente na humanidade, e não cair para fora do registro da memória humana. Como ocorre na vivência cotidiana nas enfermarias dos hospitais psiquiátricos. $\mathrm{O}$ embate entre as diferenças humanas enfrenta o risco da exclusão e da supressão, na afirmação de identidades contra diferenças a serem 
eliminadas. Como as identidades definidas nos tratamentos que excluem as diferenças faladas e atuadas por cada paciente singular.

Como se vêem os pacientes psiquiátricos? Como são vistos? As diferenças individuais e sociais (entre eles, entre eles e seus familiares, entre eles e os profissionais que atendem na instituição, entre os diferentes profissionais da mesma instituição) apresentam-se no contexto de um vasto problema, tratado com vastas confusões nomeadas por Figueiredo (1997) ao situar a clínica psicanalítica junto a outros atendimentos no ambulatório público.

Os direitos iguais, os direitos para todos, apóia-se em diferenças existentes e nos conflitos e nos movimentos que cada indivíduo faz para existir. A atenção psicossocial e os serviços sociais enfrentam esta disparidade entre metas iguais e realidade das diferenças. A proposta de Sennett (2003) sugere trocas desiguais. Ele conclui que o respeito só pode ser construído no exercício de trocas desiguais. Como são as trocas entre os pacientes e os membros da equipe? Trocas desiguais podem existir e oferecer uma saída?

A ação proposta para os pacientes mortos-vivos pretendeu construir condições iniciais para o exercício da cidadania, realizando o exercício de trocas desiguais: acompanhantes que são alunos e precisam aprender oferecem atenção e escuta aos pacientes que ensinam algo sobre a loucura e a vida no hospital, profissionais experientes pesquisam novas possibilidades de atendimento e tratamento e recuperam com os pacientes essa dimensão de não-saber e a necessidade de trabalhar em conjunto com enfoque multidisciplinar, justificado pela parcialidade de seus conhecimentos e resultados.

\section{Aspectos desenvolvidos nos grupos}

As trocas desiguais iniciais incidem sobre as diferenças individuais, incluindo as diferenças diagnósticas dos participantes; a direção inicial de subjetivação é dada pela questão sobre o futuro próximo de cada um.

A subjetivação do passado de cada um se abre a partir da escuta oferecida pelos participantes do grupo.

Uma nova posição subjetiva, uma subjetivação da mudança, coloca o futuro em íntima/êxtima ligação com o passado, porque não pode se desligar do passado, mas pode ser um corte que permite mudança.

Uma subjetivação do futuro se coloca em projetos individuais mesmo com aspectos delirantes.

As propostas de cada participante, as demandas individuais que surgiram foram encaminhadas; as reuniões institucionais foram aproveitadas para discutir o andamento do grupo (reunião de pesquisa, reunião da equipe da moradia). 


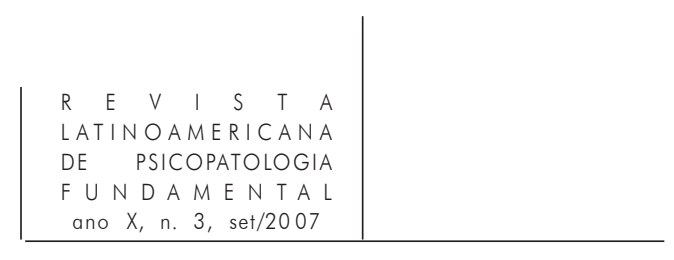

Aproveito as indicações de Agamben sobre a infância como um tempo de origem, um início histórico, uma ruptura para instalação da linguagem, que tanto socializa como enlouquece. Desejamos que o trabalho nos grupos possa gerar um novo laço, a instalação de uma relação com a linguagem que socializa, depois do tempo de isolamento no hospital.

Há contato entre eles, há uma tranqüilidade crescente que, por vezes, contrasta com as aflições dos cuidadores. A relação dependente de ser cuidado fica entre os modelos do hospital, da família, do internato, da república de colegas e estudantes, como descreveu um coordenador de um serviço residencial terapêutico.

As práticas usuais e os hábitos de higiene, alimentação, cuidados com a casa, perderam-se em tantos anos de internação hospitalar, e começam a ser reaprendidos. O cuidado de si, de acordo com a indicação de Foucault (1985) em sua História da sexualidade, apresenta em suas práticas a existência de saberes e poderes, como vemos nos métodos disciplinares. A loucura das regras excessivas, o confronto entre a posição disciplinar e de controle tem sido tema constante das discussões de equipe.

As observações sobre os processos de subjetivação podem ser exemplificadas a seguir, no Grupo Morar Junto, constatando-se a aproximação entre subjetivação e posição de cidadania, pela colocação como sujeitos de direito:

1. J., em seu poema Osmose, fala do menino que moldava o tempo, e constata: de repente senti o menino dentro de mim, a marca de um novo tempo se aproximando do cuidado com a aparência, dos ganhos de autonomia e sociabilidade.

2. P., em seu interesse pelos livros, pelos lanches da casa, inscreve a marca de sua letra bem desenhada, de seu bolo bem-feito, aproxima sua vida atual da casa que teve, da escola que freqüentou e do direito de ter novamente casa, documentos, livros.

3. N., que antes queria voltar para junto da mãe, agora quer um novo namorado além daquele que teve, e que no delírio é um índice de sua marca traumática; a casa e a feminilidade aproximam sua posição de um além do trauma, além da aderência aos cuidados maternos, para adquirir um novo direito de fugir disso.

4. C., com seu sorriso diante do armário e das coisas bem guardadas, mostra uma possibilidade de vida nova, mais segura, mais arrumada, como a lembrança de ter sido copeira resgata no modo como ocupa a casa.

5. M. iniciou a busca das origens familiares, a nobreza dos Orleans e Bragança, a aquisição de adereços e itens de vaidade feminina, as pesquisas, mostrando seu desejo de manter o que tem de bom; falando inglês com o filho por telefone, assume o direito de ter uma história e continuá-la. 
6. A. escolheu se comunicar novamente e recomeçar um laço, que se efetiva no reencontro da filha, da neta e de alguns conhecidos, para tentar ampliar seus direitos até a recuperação possível da saúde física tão negligenciada no hospital.

7. S., ao se colocar de pé para recomeçar um novo tempo de vida, dizendo vamos agora!, depois de tanto tempo só deitada e coberta, marca a diferença entre o longo período de hospitalização, o horror dos eletrochoques que mencionou, e a possibilidade de conversar, cuidar de si, usar um benefício que demorou tanto.

8. E., com sua recusa em participar das reuniões, em conhecer a casa, marcou uma posição conservadora em relação ao hospital já desterritorializado por ela; tendo transformado o hospital no que ele não é, estabelecendo relações impróprias para o hospital, cavou sua saída, e irá para uma moradia, após nossa insistência em apontar um caminho de saída.

9. T. é a nossa exceção, ela é aquela com quem não falamos porque foi transferida sem passar pelos grupos - marca a falta de sincronia do trabalho de equipe multidisciplinar, mas marca também a diacronia de um trabalho que continua na equipe.

Segue-se o relato extraído do caderno de pesquisador sobre as duas últimas reuniões, nos dias 21 e 28 de março de 2006, com comentários feitos a partir da reunião de equipe que aconteceu entre as duas reuniões:

Décima-nona reunião:

Foram redefinidos os acompanhamentos para cada morador (...), os responsáveis pelo acompanhamento das posições subjetivas (especializandos da Clínica Psicanalítica), que deve sustentar a singularidade na nova etapa de vida e na perspectiva do tratamento de cada um.

A comunicação destas definições foi feita para todos.

A oferta de escuta para os cuidadores foi feita e ficará a cargo dos especializandos, sob minha orientação, com a direção de construção do trabalho de cuidado, além da proximidade familiar que já se manifesta. Os cuidadores serão convidados a participar das reuniões de equipe.

M. tem falado de gravidez, falou com seu filho nos Estados Unidos, parece procurar pessoas de sua família pelos sobrenomes. Recupera sua vaidade, fuma muito, gosta de comer e briga com a necessidade de regime.

P. fica sem dinheiro para comprar coisas elementares para sua higiene pessoal; o coordenador da casa conseguirá adiantar dinheiro para tirar segunda via de seus documentos, para que possa em seguida solicitar um auxílio a que tem direito.

J. retomou sua análise, encaminhou reclamações das atitudes da cuidadora do fim de semana, falou em nome de todos, depois que entregaram, nessa reunião, 


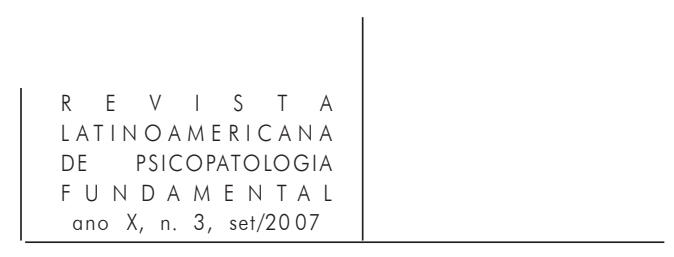

escritos e desenhos, manifestações de cada um relacionadas à mudança para a casa, a saída do hospital e a perspectiva de uma nova etapa de vida.

P. escrevia, copiava trechos de um livro de Monteiro Lobato com uma letra desenhada, bonita, caprichada, trocando canetas e cores.

C. ditou palavras para mim, entre elas copeira e copeiro, profissão dela e do pai; perguntou sobre o nascimento do bebê de uma assistente social (que havia tomado todas as providências para aprontar a moradia e a ida deles).

Desenhos de M., A., J., N., mostram o que precisa ser guardado na casa que os acolhe: o que é de cada um.

Observações da reunião de equipe:

Curiosamente, uma assistente social (coordenadora de uma das moradias) chamou o varal montado na casa de jardim de infância - e aproveito para destacar aqui um tempo de origem, um início histórico, como localizou Agamben no significado de uma ruptura para instalação da linguagem, que tanto enlouquece como socializa. Afirmo meu desejo de que a infância dos moradores do Grupo Morar Junto possa gerar um novo laço depois do isolamento vivido no hospital.

Há pouco contato atualmente entre eles, mas há uma tranqüilidade crescente que por vezes contrasta com as aflições dos cuidadores. A relação dependente de ser cuidado fica entre os modelos do hospital, da família, restando a indicação de um psicólogo (coordenador de uma das moradias) - a república de estudantes como novidade da situação de morar junto.

As práticas usuais e os hábitos de higiene, alimentação, cuidados com a casa, começam a ser praticados e até reaprendidos. Lembramos de Foucault com seus estudos sobre o cuidado de si, que revelam saberes e poderes presentes nos métodos disciplinares, exercidos com excessivo controle e exageradas exigências por uma das cuidadoras que pretende ser sempre obedecida.

Vigésima reunião:

Diante do varal que atravessa a sala da moradia, perguntamos: o que pode caracterizar a casa deles como casa deles? Lembramos as demandas que formulavam no hospital: dá um cigarro, dá um real, dá um café, dá pra sair? e alguns perguntam por quanto tempo poderão permanecer ali na moradia. Continuam com a medicação e não sabem o que poderão fazer. Indicamos que é apenas um começo. Um pede bolo, outro sai mostrando seus dentes novos, alguém fala em comprar roupa, alguém lembra de uma pessoa da família, algumas colocações deliróides apresentam situações de gravidez, namoros, dinheiros guardados, sobrenomes importantes.

No ambiente da sala da casa, uma refeição está sendo servida, a televisão é ligada enquanto as conversas se alternam, o telefone e a campainha tocam. Conto para um dos moradores da casa, quando sai do quarto e entra na sala, o que está acontecendo, e sua resposta é um sorriso... 
Conclui-se a passagem da situação de catástrofe subjetiva para posições subjetivas ativas e desejantes. No hospital, o funcionamento dos grupos tem seguido um modo de conexões em rede de relacionamentos: os acompanhantes chamam os pacientes, alguns vêm para a sala de reunião no setor de enfermagem da enfermaria feminina, outros não vêm, e vamos até eles para comunicar aspectos da reunião, perguntar como estão e convidá-los para a próxima. Mantemos um mesmo horário e um mesmo dia, um mesmo local - estas referências que vão organizando a catástrofe, que seguem o mesmo princípio de conexões em rede, mas já com um formato mais organizado.

Uma estratégia operativa de enfoque psicanalítico define o trabalho com o grupo. A metodologia de trabalho das oficinas terapêuticas procura seguir as indicações e as experiências de tantos profissionais que escreveram a respeito, textos organizados por Costa e Figueiredo (2004). O funcionamento das oficinas terapêuticas procura “... restabelecer a cidadania da pessoa com transtornos mentais através da desconstrução do modelo asilar. As oficinas, além de terapêuticas, são promotoras do sujeito" (p. 7). Trabalho, produto, renda, autonomia - uma série que supõe um trabalho psíquico na direção de uma subjetivação apoiada na auto-sustentação dentro de um sistema de reinserção social, através de ações que envolvem o trabalho, a criação de um produto, a geração de renda e a autonomia: um sujeito passa a ocupar um lugar nesse sistema, com condições de manter sua ocupação. O trabalho psíquico de subjetivação orientado por uma psicanalista possibilitou a criação de um produto: a subjetivação de uma nova posição.

A proposta de desenhos e escritos no final dos grupos partiu do conceito de desconstrução de Derrida $(1967,1972,1976)$ para sistematizar o rompimento da identidade de doente internado, e utilizar a escrita ou o desenho como método de construir/destruir registros de memória. Na direção de uma nova construção, o método de uma escrita virtual está desenvolvido na tese de doutorado (Guimarães, 1999), que segue as indicações democráticas de uma política da escrita como propõe Rancière (1995). Os pacientes poderão escrever ou desenhar algo de seu futuro?

Como podemos construir um futuro? O que percebemos de nossa vida tem realidades diversas: experiências sensíveis, representação, realidade psíquica, realidade virtual, ficção, experiência, deserto do real... O que já está escrito em nossa memória? Por que a prática hospitalar não cultiva a memória e a história de cada paciente? 


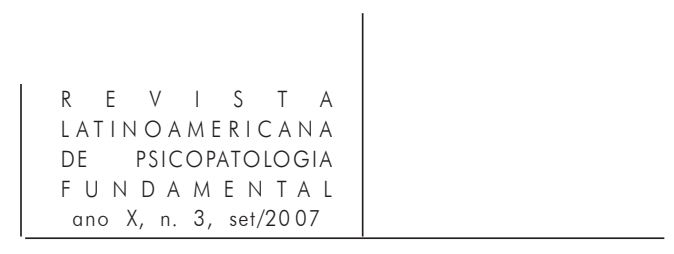

Uma dimensão impossível faz parte do campo de convivência e de conveniência de um trabalho psicanalítico. Por isso, assumimos os casos mais difíceis para pesquisar a mudança subjetiva ou a saída da catástrofe subjetiva para uma singularidade na subjetivação que indica um desejo, como vimos nas novas posições de cada paciente.

A pesquisa procura as condições do que pode aparecer como catástrofe subjetiva e as condições de subjetivação que podem expressar singularidades ligadas à reabilitação de cada paciente.

A pesquisa começa a colher seus achados, e deve prosseguir com outros grupos de pacientes e outras condições de saída de internação.

O desejo do psicanalista (o psicanalista se coloca como desejante diante da perspectiva de futuro, e não como efetivo agente de transformação) manifestase no convite e nas propostas para as reuniões, em sua atuação nas reuniões, e é o agente causador das posições dos participantes, apoiado no projeto de mudança empreendido pelo IPUB com as moradias assistidas e as equipes multidisciplinares envolvidas no processo de des-hospitalização de pacientes crônicos.

As reuniões da equipe multidisciplinar (onde se insere a pesquisa de saídas de pacientes internados no IPUB/UFRJ) contam com a presença da coordenadora do projeto (psiquiatra), dos coordenadores das moradias (assistente social e psicólogo), da pesquisadora em psicanálise, dos acompanhantes terapêuticos, e eventualmente dos cuidadores e promotores de atividades específicas (educação física, filmagem, nutrição).

O trabalho de psicanalista tem se definido aí pela promoção do laço social entre moradores e cuidadores na moradia, entre as equipes clínicas responsáveis pelos projetos terapêuticos de cada morador, entre os participantes da reunião e demais profissionais envolvidos no acompanhamento da recuperação possível da saúde e da cidadania - para que o hospital tente ser um lugar de passagem e tratamento, não o Cemitério dos vivos como escreveu Lima Barreto:

Eu ali, naquele hospício, no meio da vida, com tantas dores na vida, as que me vieram sem culpa minha, as que eu mesmo engendrei, cheio de vida e de bondade, não era bem a morte que eu queria, não era o aniquilamento da minha pessoa, a sua fragmentação até o infinito, nas coisas e nos seres, era outra vida, mais cheia de amor, de crença, de ilusão, sem nenhum poder de análise e isenta de toda e qualquer capacidade de exame sobre mim mesmo.

\section{Referências}

Agamben, Giorgio (1995). Homo Sacer: o poder soberano e a vida nua I. Belo Horizonte: UFMG, 2004. 
Infância e história. Destruição da experiência e origem da história. Belo Horizonte: UFMG, 2005.

Barreto, Lima (1919-1920). Cemitério dos vivos. Rio de Janeiro: Planeta, 2004.

Bauman, Zygmunt (1997). O mal-estar da pós-modernidade. Rio de Janeiro: Jorge Zahar, 1998.

(2001). Comunidade - a busca por segurança no mundo atual. Rio de Janeiro: Jorge Zahar, 2003.

Belaga, Guillermo (compilador). La urgencia generalizada. La práctica en el hospital. Buenos Aires: Grama ediciones, 2004.

Costa, Clarice Moura e Figueiredo, Ana Cristina (org.). Oficinas terapêuticas em saúde mental - sujeito, produção e cidadania. Rio de Janeiro: Contra Capa, 2004.

Costa, Jurandir Freire (1994). A ética e o espelho da cultura. 3. ed. Rio de Janeiro: Rocco, 2000.

III Conferência Nacional de Saúde Mental, publicação do Ministério da Saúde, 2001.

Deleuze, Gilles (1968). Diferença e repetição. Rio de Janeiro: Graal, 1988.

Derrida, Jacques (1967). A escritura e a diferença. São Paulo: Perspectiva, 1995.

(1972). A farmácia de Platão. São Paulo: Iluminuras, 1991.

Glossário. Silviano Santiago (superv.). Rio de Janeiro: Francisco Alves, 1976.

Figueiredo, Ana Cristina (1997). Vastas confusões e atendimentos imperfeitos. 3. ed. Rio de Janeiro: Relume-Dumará, 2002.

Foucault, Michel. História da sexualidade III. O cuidado de si. Rio de Janeiro: Graal, 1985.

Freud, Sigmund (1900). A interpretação dos sonhos. In: Edição Standard Brasileira das Obras Psicológicas Completas. Rio de Janeiro: Imago, 1976. v. IV e V.

(1923). O ego e o id. In: Edição Standard Brasileira das Obras Psicológicas Completas. Rio de Janeiro: Imago, 1976. v. XIX.

Guimarães, Nelisa de Araújo. A escrita e o virtual. 1999. 174p. Tese (doutorado em Comunicação e Cultura), Universidade Federal do Rio de Janeiro, Rio de Janeiro.

LaCAN, Jacques (1963). Kant com Sade. In: Escritos. Rio de Janeiro: Jorge Zahar, 1998. (1971-1972). Ou pior. In: Outros Escritos. Rio de Janeiro: Jorge Zahar, 2003. (1971-1973). O seminário. Livro 20. Mais, ainda. Rio de Janeiro: Jorge Zahar, 1982.

Negri, Toni (1998). Exílio, seguido de Valor e Afeto. São Paulo: Iluminuras, 2001. 


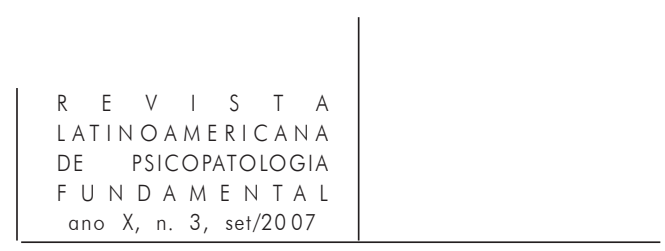

Negri, Toni; HaRdT, Michael (2000). Império. Rio de Janeiro: Record, 2001.

Rancière, Jacques. Políticas da escrita. Rio de Janeiro: Editora 34, 1995.

SEnetT, Richard (2003). Respeito - a formação do caráter em um mundo desigual. Rio de Janeiro: Record, 2004.

Simondon, Gilbert. L'individu et sa génèse physico-biologique. Paris: PUF, 1964.

Zizer, Slavoj (2002). Bem-vindo ao deserto do real! Estado de sítio! São Paulo: Boitempo, 2003.

\section{Resumos}

Pacientes con gravísimos disturbios mentales deben ser respetados como ciudadanos. Un trabajo con enfoque psicoanalítico es realizado en equipo multidisciplinar con grupos de pacientes que están saliendo del hospital psiquiátrico y procurando una nueva modalidad de vida. Lazos sociales y posiciones subjetivas son efectos positivos observados.

Palabras claves: Psicoanálisis, Hospital Psiquiátrico, salida de internación, subjetivación en la psicosis

Les patients souffrant de graves troubles mentaux méritent notre respect en tant que citoyens. Un travail de rapport psychanalytique a été réalisé par une équipe multidisciplinaire avec des groupes de patients sortant de l'hôpital psychiatrique à la recherche d'une nouvelle façon de vivre. Les liens sociaux et les positions subjectives ont été les résultats positifs observés.

Mots clés: Psychanalyse, Hôpital Psychiatrique, sortie d'internement, subjectivation dans la psychose

Patients with severe mental disorders must be respected as citizens. A psychoanalytic approach is used by a multidisciplinary team working with patients who are leaving a mental hospital and searching for new ways of life. Social relations and subjective positions are the positive results observed.

Key words: Psychoanalysis, psychiatric hospital, leaving the hospital, subjectivation in psychosis 